This work was done during the tenure by one of us (M. F. B.) of a research award of University College, Hull.

Mary E. Bromhead (Mrs. Webster)* Paul G. 'Espinasse

Department of Zoology,

University College,

Hull. July 15.

* Now at the Department of Zoology, University, Sheffield.

1 Duran-Revnals, F., Bact. Rev., 6, 197 (1942). Meyer, K., Physiol. Rev., 27, 335 (1947).

${ }^{2}$ Greenwood, A. W., and Blyth, J. S. S., Proc. Roy. Soc., B, 118, 97 (1935). 'Espinasse, P. G., Proc. Zool. Soc., 109, 247 (1940).

s Hechter, O., Fed. Proc., 6, 126 (1947).

- Hechter, O., Ann. N.Y. Acad. Sci., 52 (7), 1028 (1950).

'Espinasse, P. G., Nature, 144, 1013 (1939).

- Hechter, O., Dopkeen, S. K., and Yudell, M. H., J. Pediat., 30, 645 (1947).

\section{Seasonal Fluctuations in the Degree of Hatching from Cysts of the Potato Root Eelworm}

THE rate of hatching of larvæ from cysts of the potato root eelworm $H$. rostochiensis Woll. during in vitro hatching tests has been found by many workers to show seasonal fluctuations, a high level of larval emergence during the summer months declining to a negligible hatch during the winter.

After a series of experiments to measure this fluctuation quantitatively, Lownsbery concludes ${ }^{1}$ that the phenomenon is inherent in the physiology of the worm and is not correlated with any seasonal difference in the leachings used. He agrees with Reinmuth ${ }^{2}$ that exposure to winter conditions is not necessary for the induction of the dormant period. His attempts to break the dormancy by temperature and humidity control were unsuccessful. The phenomenon of winter" dormancy was also demonstrated by Triffitt ${ }^{3}$.

We have been conducting in vitro hatching tests for a number of years, and now wish to record that for the past three years we have not found any apparent diminution in the 'hatchability' of the cysts during the winter months. Cysts floated from soil collected during the spring and summer months are rolled from the debris and stored in small bottles or large tubes in a dark cupboard at room temperature. The corks are notched at one side to allow free air circulation. No attempt is made to maintain a uniform temperature; the normal fluctuations in room temperature appear to have no harmful effect provided the temperature does not fall below about $15^{\circ} \mathrm{C}$. The root diffusate used in all the hatching tests is collected during the summer, pooled, mixed and then stored at about $3^{\circ}-4^{\circ} \mathrm{C}$. When setting up a hatching test, the cysts are weighed into batches on a miero-balance ${ }^{4}$ and soaked in tap water for about fourteen days. Afterwards, the water is removed and root diffusate added, when normal hatching occurs.

Our experience indicates that Heterodera cysts are not essentially subject to a winter dormancy. The low hatches during the winter months encountered by other workers probably result from the influence of external environment, possibly soil conditions at the time of cyst extraction. This view is supported by the fact that cysts washed from soil taken from fields in late autumn or winter show an apparent dormancy, whereas cysts recovered from the above soil during the summer and stored under the same conditions do not. The apparent dormancy encountered cannot be of so fundamental a nature as suggested by Lownsbery ${ }^{1}$, since cysts recovered from soil and stored under the conditions described above are capable of hatching at the normal rate throughout the winter months.

\author{
Elizabeth R; tD \\ Rothamsted Experimental Station, \\ Harpenden, Herts. \\ July 8. \\ ${ }^{1}$ Lownsbery, B. F., Phytopath., 41 (10), 889 (1951). \\ " Reinmuth, E., Z, Pflanzenkrankh., 39, 241 (1929). \\ ${ }^{3}$ Triffitt, M. J., J. Helminth., 8, 185 (1930). \\ 4 Fenwick, D. W., and Reid, E., J. Helminth., 25 (3/4), 173 (1951).
}

DAVID W. FENWICK

\section{Experimental Induction of Male Cones in Pinus sylvestris}

IT is well known that seedling trees of Pinus sylvestris, in common with those of many other woody species, pass through a juvenile period, during which no reproductive organs are formed. The first female cones appear at the age of about seven years, while male cones are not usually formed until several years later. These male cones generally appear first on the lower, older branches.

In 1950, I observed that certain trees of about twelve years of age growing in plantation at Oxshott Common, Surrey, bore numerous female cones; but none of the trees showed branches which had passed to the male condition. Closer inspection revealed a few isolated male shoots, however, and in every case these were borne on vegetative shoots of which the terminal bud had failed to develop in the previous season, due to attack by an insect (the identity of which has not yet been determined). As a result of this destruction of the terminal bud, the uppermost. 'dwarf shoots' (bearing paired needles) had been stimulated to produce a resting bud, and it was in such buds that male cones had developed. I have since observed similar examples on several occasions in various localities.

In order to test whether experimental removal of the terminal buds would have the same effect, a considerable number of shoots on the lower branches of ten of the trees in question were disbudded by hand in January 1951. One or two of the uppermost dwarf shoots on each treated shoot developed resting buds during the summer of 1951, and these unfolded in the spring of 1952. Inspection in May 1952 revealed that 242 out of a total 472 treated shoots (that is, 53 per cent) had developed male shoots, and these were the only ones present on the trees in question (apart from a few isolated male cones again found to be associated with insectdestruction of the normal terminal bud). In some branches, 100 per cent of the treated shoots had produced male shoots.

Thus, experimental disbudding may be used for hastening the production of male cones in young trees of $P$. sylvestris and might prove a valuable addition to the other techniques, such as bark ringing and strangulation, already used in forest tree breeding.

The results of the present experiments correspond in certain respects with the experimental induction of lateral flower buds in the Haden mango by removal. of the terminal bud ${ }^{1}$.

Department of Botany,

University, Manchester.

\section{P. F. WAREING}

'Reece, P. C., Furr, J. R., and Cooper, W. C., Amer. J. Bot., 33, 209 